difficulty which a foreign body inside the lens may have in escaping through the capsule; secondly, the production in consequence of an apparent rotation of the lens; and thirdly, the rapidity with which sight may be restored after a traumatic cataract.

\title{
TRANSLATION
}

\section{RECONSTITUTION OF THE LOWER CUL-DE-SAC BY CUTANEOUS AUTOPLASTY*}

\author{
BY \\ MARCEL DANis, \\ MÉDECIN-ADJOINT DE L'ARMÉE BELGE
}

Penetrating wounds of the orbit by war projectiles often provoke extensive destruction of the conjunctiva. The eye bursts, empties itself more or less completely of its contents, and is, as it were, reduced to pulp. Enucleation of the remaining stump is rendered very difficult.

The conjunctiva, torn in many places, cicatrizes irregularly, while leading to contractions which often entail the almost total disappearance of the lower cul-de-sac. The introduction and the keeping in place of an artificial eye are then impossible.

In recent cases the introduction of a porcelain shell, pierced by a central hole which permits of the escape of the conjunctival secretions, guides the conjunctiva in its cicatrization, and makes the ultimate wearing of an artificial eye possible.

In long standing cases we have employed paraffin spheres of increasing size; the distension produced by them lengthens the cicatricial bands and enlarges the cavity. Under these circumstances it may be possible to introduce an appropriate prothesis. But in certain cases the retraction is such that the inferior cul-de-sac has completely disappeared. Progressive dilatation is inefficacious, and surgical means alone are likely to be of use. When the conjunctiva is absent it is necessary to employ a graft.

Different kinds of graft have been described, as, for example, the hetero-conjunctival graft with conjunctiva from the rabbit or the dog, the dermo-epidermic graft of Thiersch, the graft of buccal mucous membrane, the graft of vaginal mucous membrane, and the graft of frog's skin.

Several methods of cutaneous autoplasty are described in the Encyclopedie française d'ophtalmologie: the operations of Dieffenbach, Snellen, Harlan, Rogman, and Samelsohn.

- Translated from Ann. d'Ocul., February, 1916. 
The procedure which we have employed is a modification of Snellen's operation. The technique is as follows: The operation is done in two stages :

\section{First Stage.}

(1) An incision is made from the external angle of the eyelids having a length of about 1 centimetre.

(2) The cutting of a temporo-frontal flap, of which the length should be one-third longer than the distance of the external point of the canthotomy from the caruncle, and its breadth about $1 \frac{1}{2} \mathrm{~cm}$. to $2 \mathrm{~cm}$. at the base. It ends in a rounded point. The flap begins $1.5 \mathrm{~cm}$. to $2 \mathrm{~cm}$. below the level of the line of the canthus and the internal incision passes to the external extremity of the canthoplasty.

(3) Dissection, haemostasis, and toilette of the flap.

(4) In consequence of the canthoplasty and the infero-external incision of the temporo-frontal flap, the lower eyelid may be drawn downwards. The conjunctiva of the inferior cul-de-sac is then incised and dissected along the two edges of the incision.

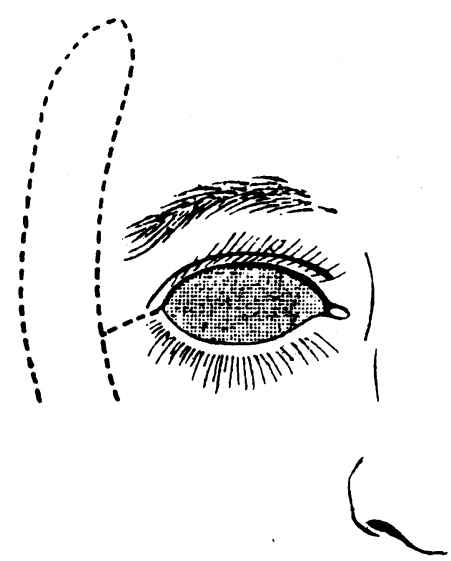

FIG. 1.

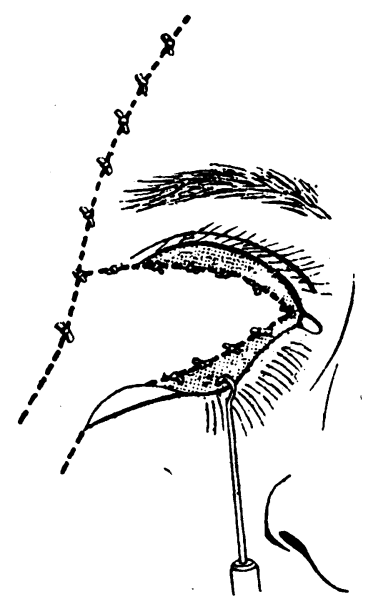

FIG. 2.

(5) The temporo-frontal flap is turned at about an angle of 90 degrees, and its summit is fixed near the caruncle, between the two lips of the dissected conjunctiva, and is fixed there by a point of suture.

(6) The cutaneous flap is sutured to the two conjunctival lips.

(7) The skin of the temple is sutured.

(8) The position of the new cul-de-sac is ensured by a loop of suture emerging at the level of the cheek. 


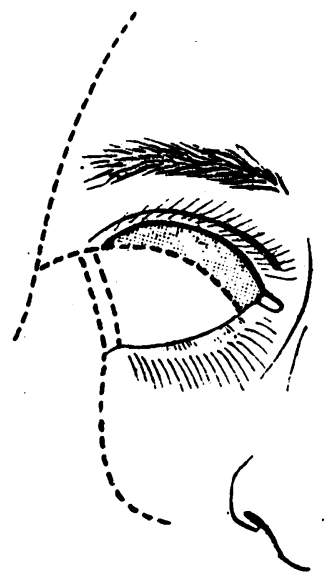

The second stage of the operation is undertaken after complete cicatrization.

Fig. 3.

\section{Second Stage.}

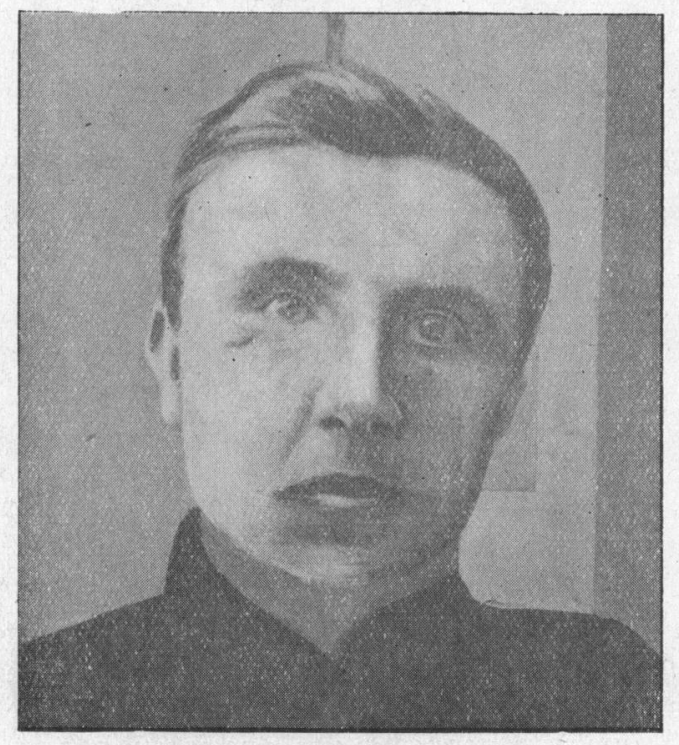

FIG. 4.

(1) Division of the pedicle of the temporo-frontal flap.

(2) One excises a rectangle of skin, the breadth of which is 3 to $4 \mathrm{~mm}$.; one of the extremities of this rectangle corresponds to the external angle of the upper eyelid; the other to the external 
angle of the retracted lower eyelid. It is in the gutter thus formed that one places the lower eyelid, freed by an incision, oblique below and inside, and slightly curvilinear at its lower extremity.

Sutures.-In order to avoid all retraction, before fixing the points of suture, we place a provisional prothesis in the orbital cavity.

The two advantages of the, operation described over that of Snellen are the following:

1. Better nutrition of the flap, of which the base may be larger and which is not nipped or rendered anæmic by the button-hole which Snellen makes near the external angle.

2. The conjunctival and cutaneous suturing is rendered much easier by the liberation of the lower eyelid.

We have had occasion to employ the operation described upon two wounded soldiers in the Belgian ophthalmological service of No. 30 Complementary Hospital at Rennes.

First case.-D.- infantryman. Penetrating wound of the eye by rifle bullet. The bullet must have entered through the cornea (there was no lesion of the skin of the eyelids) and emerged behind the ear. Enucleation the same day in a hospital at the front. We saw the patient 37 days after enucleation. The lower cul-de-sac could not be said to exist ; the conjunctiva was retracted and cicatricial, and the introduction of an artificial eye was impossible. The operation, which I have described, made the wearing of a prothesis very easy (see Fig. 4).

Second case.-S. M., aviation mechanician, was wounded by a fragment of a bomb from an aeroplane. The eye was enucleated in a hospital at the front.

On arrival at Rennes we found.-A cicatricial band of the upper eyelid, $1 \mathrm{~cm}$. from the internal angle, and ectropion of the outer part of the upper eyelid. The lower cul-de-sac was completely bridled by cicatricial bands, drawing the lower eyelid towards the depths of the orbit, the cul-de-sac being completely absent.

In order to correct the ectropion, freshening and suture of the upper eyelid, and operation according to the technique described above. After this operation the wearing of an artificial eye became quite easy.

S. S.

\section{ANNOTATIONS}

\section{A Representative Council of British Ophthalmologists}

A meeting of ophthalmic surgeons was held on May, 2 last at the house of the Royal Society of Medicine, for the purpose of forming a representative council empowered to take action in matters of 